Article

\title{
One-Day Molecular Detection of Salmonella and Campylobacter in Chicken Meat: A Pilot Study
}

\author{
Andrea Zendrini ${ }^{1,2} \mathbb{D}$, Valentina Carta ${ }^{3}$, Virginia Filipello ${ }^{3,4} * \mathbb{D}$, Laura Ragni $^{3}$, Elena Cosciani-Cunico ${ }^{3}$, \\ Sara Arnaboldi ${ }^{3}$ (D), Barbara Bertasi ${ }^{3}$ (D) Niccolò Franceschi ${ }^{1}$, Paolo Ajmone-Marsan ${ }^{1}$, Dario De Medici ${ }^{5}$ D \\ and Marina Nadia Losio ${ }^{3,4}$
}

1 Department of Animal Science, Food and Nutrition-DIANA, Università Cattolica del Sacro Cuore, Via E. Parmense, 84, 29122 Piacenza, Italy; a.zendrini@unibs.it (A.Z.); niccolo.franceschi@unicatt.it (N.F.); paolo.ajmone@unicatt.it (P.A.-M.)

2 Department of Molecular and Translational Medicine, University of Brescia, Viale Europa, 11, 25123 Brescia, Italy

3 Department of Food Safety, Istituto Zooprofilattico della Lombardia e dell'Emilia Romagna, Via A. Bianchi, 9, 25124 Brescia, Italy; valentina.carta@izsler.it (V.C.); laura.ragni@izsler.it (L.R.); elena.coscianicunico@izsler.it (E.C.-C.); sara.arnaboldi@izsler.it (S.A.); barbara.bertasi@izsler.it (B.B.); marinanadia.losio@izsler.it (M.N.L.)

4 National Reference Centre for Emerging Risks in Food Safety-CRESA, Istituto Zooprofilattico della Lombardia e dell'Emilia Romagna, Via G. Celoria, 12, 20133 Milan, Italy

5 Department of Food Safety and Veterinary Public Health, Istituto Superiore di Sanità, Viale Regina Elena, 299, 00161 Rome, Italy; dario.demedici@iss.it

* Correspondence: virginia.filipello@izsler.it; Tel.: +39-030-2290-781

Citation: Zendrini, A.; Carta, V.; Filipello, V.; Ragni, L.; Cosciani-Cunico, E.; Arnaboldi, S.; Bertasi, B.; Franceschi, N.; Ajmone-Marsan, P.; De Medici, D.; et al. One-Day Molecular Detection of Salmonella and Campylobacter in Chicken Meat: A Pilot Study. Foods 2021, 10, 1132. https: / / doi.org/10.3390/foods10051132

Academic Editor: Michel Federighi

Received: 3 May 2021

Accepted: 14 May 2021

Published: 19 May 2021

Publisher's Note: MDPI stays neutral with regard to jurisdictional claims in published maps and institutional affiliations.

Copyright: (c) 2021 by the authors. Licensee MDPI, Basel, Switzerland. This article is an open access article distributed under the terms and conditions of the Creative Commons Attribution (CC BY) license (https:// creativecommons.org/licenses/by/ $4.0 /)$.
Abstract: Salmonella and Campylobacter ssp. are bacterial pathogens responsible for most foodborne infections in EU countries. Poultry serves as a reservoir for these pathogens, and its important role in the meat industry makes it essential to develop a rapid detection assay able to provide results in one day. Indeed, the rapid identification of foodborne pathogens is an important instrument for the monitoring and prevention of epidemic outbreaks. To date, Salmonella and Campylobacter screening is mainly conducted through molecular methods (PCR or real-time PCR) performed after 18-24 h long enrichments. In this study, we evaluated short enrichments $(0,2,4$, and $6 \mathrm{~h})$ combined with a colorimetric loop-mediated isothermal AMPlification (LAMP) or real-time PCR to detect Salmonella and Campylobacter in poultry meat contaminated at different concentration levels $\left(10^{1}\right.$, $10^{3}$, and $10^{5} \mathrm{CFU} / \mathrm{g}$ ). Our results show that real-time PCR allows the detection of Salmonella and Campylobacter, even after shorter enrichment times than prescribed by ISO references; particularly, it detected Salmonella down to $10^{1} \mathrm{CFU} / \mathrm{g}$ since $\mathrm{T} 0$ and Campylobacter from $10^{3} \mathrm{CFU} / \mathrm{g}$ since $\mathrm{T} 0$. Detection with LAMP was comparable to real-time PCR without the requirement of a thermal cycler and with shorter execution times. These characteristics make colorimetric LAMP a valid alternative when one-day results are needed, improving the timely identification of positive meat batches, even in the absence of specialized instrumentation.

Keywords: LAMP; Campylobacter; Salmonella; poultry; foodborne diseases

\section{Introduction}

Salmonella enterica and Campylobacter spp. are bacterial pathogens that cause the majority of foodborne infections in EU countries, being the second and first cause of foodborne diseases in 2019, respectively. More specifically, Salmonella was responsible for 87,923 human cases, and Campylobacter spp. was reported in 220,682 clinical cases [1].

Salmonella is a Gram-negative, rod-shaped bacterium with a facultative anaerobic metabolism belonging to the Enterobacteriaceae family. The genus Salmonella belongs to two broad species, namely Salmonella enterica and Salmonella bongori. Salmonella enterica represents the most pathogenic species, and includes over 2600 serovars [2,3]. Some 
serovars are species-specific, while others are highly adapted to a wide range of animal hosts, and are responsible for foodborne infections, causing mild to severe enteric diseases in humans [3]. The serovars more frequently involved in foodborne transmission are S. enterica ser. Enteritidis (S. Enteritidis) and S. Typhimurium (including its monophasic variant), which are frequently found in food of animal origin together with other serovars, like $S$. Infantis and $S$. Dublin [1-3].

In Europe, most salmonellosis outbreaks and infections are linked to the consumption of poultry meat, eggs, and their derived products [2]. Indeed, some strains of Salmonella, including $S$. Enteritidis and $S$. Typhimurium, frequently colonize the enteric tract of avian species without detectable symptoms and can survive along the processing chain, causing contamination [4]. Campylobacter spp. are Gram-negative, non-spore-forming bacteria belonging to the Campylobacteriaceae family that includes 22 different species, among which Campylobacter jejuni and Campylobacter coli represent the main cause for human gastroenteritis. Clinical manifestations of campylobacteriosis can be severe, with possible sequelae like Guillain-Barrè syndrome, reactive arthritis, and irritable bowel syndrome [5]. The main reservoir for foodborne transmission of $C$. coli and $C$. jejuni are poultry species, and handling and eating raw or undercooked chicken meat is the main risk factor for human infection, accounting for up to $24.2 \%$ of all of the Campylobacter spp. infections in the EU [6].

The testing and rapid detection of pathogenic microorganisms in foodstuffs, like Salmonella and Campylobacter, is crucial to identify contaminated foods and contain the spread of the pathogen before it leads to a serious outbreak.

The PCR amplification of specific DNA and RNA fragments has become the preferred method for the detection of microorganisms in foods. In particular, real-time PCR (RT-PCR) has gained ever-growing importance in the molecular screening of foodborne pathogens.

In recent years, many other amplification techniques have been developed to improve PCR in terms of sensitivity, affordability, and rapidity [7]. Loop-mediated isothermal amplification (LAMP) is one of the most widely used isothermal methods, detecting bacteria, DNA viruses, and, recently, parasites [8-12]. Considering that LAMP is a simple operating assay with the ability to rapidly detect pathogens in at-risk inhibition matrices, it has great potential in the foodborne diseases field [13]. Indeed, it was successfully applied to some main foodborne pathogens, such as Escherichia coli, Salmonella, Listeria monocytogenes, and Staphylococcus spp., demonstrating the possible application in the clinical diagnosis and surveillance of infection diseases [14-17].

To be performed, LAMP requires 2/3 pairs of primers that amplify the target region through elongation via a hairpin structure with stem loops at each end [18]. A DNA polymerase featuring high strand displacement activity (e.g., the Bst polymerase from Bacillus stearothermophilus) is also required. Despite LAMP being more complex than PCR in terms of setting up and optimization, it provides several advantages: (i) thanks to the strand displacement activity of the polymerase, LAMP is an isothermal reaction, thus eliminating the need for a thermal cycler; (ii) amplification is higher and faster than PCR, occurring in less than $60 \mathrm{~min}$; (iii) LAMP is less sensitive to inhibitors that normally hamper PCR (e.g., detergents, salts, or lipids); and (iv) DNA amplification can be observed at a glance, without any specific equipment, if proper chemicals are added in the reaction mix (e.g., colorimetric reporters). These benefits make the LAMP reaction a tool in all applications needing rapid tests, such as on-field analyses (e.g., on-site production quality monitoring and control of third-country imports). Considering the fact that poultry consumption reached 120 million tons in the 2016-2018 period and the role of chicken as the major reservoir for Campylobacter and Salmonella infection [1], it is pivotal to ensure the fast screening of these bacteria in poultry products to grant food safety. To date, Salmonella and Campylobacter screening by RT-PCR is completed within $24-48 \mathrm{~h}$ from sample receipt and registration. However, a relevant lapse of this time is used for pathogen growth $(18 \mathrm{~h}$ for Salmonella and $40 \mathrm{~h}$ for Campylobacter) in a proper medium (the so-called enrichment phase). Indeed, the possibility to shorten the enrichment phase would represent an enormous 
time-saving option. Therefore, the objective of this study was to test the effect of short enrichment times $(0,2,4$, and $6 \mathrm{~h})$ on the detection of Salmonella and Campylobacter in experimentally contaminated poultry meat and to develop a one-day workflow to improve the timely diagnosis of these two pathogens. Pathogen detection was carried out both with RT-PCR and colorimetric LAMP, the latter representing an additional rapid, cost-effective, user friendly, and well-established alternative for food and feed screening of pathogens at the point of care (POC) $[8,19,20]$.

\section{Materials and Methods}

\subsection{Experiment Design and Experimental Contamination}

To evaluate the ability of the LAMP assay to detect Salmonella and Campylobacter spp. in poultry meat, an experimental trial was set up. Four batches of ground chicken meat, $1200 \mathrm{~g}$ each, were spiked with different concentrations of either Salmonella or Campylobacter spp. (two batches each). As previously described [21], for each pathogen, a bacterial suspension of three different strains was prepared (Table 1). Each strain was incubated separately in BHI broth at $37^{\circ} \mathrm{C}$ for $22 \pm 2 \mathrm{~h}$ for Salmonella, and in Bolton broth at $41.5^{\circ} \mathrm{C}$ with $5 \% \mathrm{CO}_{2}$ for $24 \pm 2 \mathrm{~h}$ for Campylobacter spp. Then, the broths were re-incubated in fresh media at the same conditions to ensure that most of the cells were in the same physiological state. The broth concentration was titrated on blood agar, and $10^{3} \mathrm{CFU} / \mathrm{mL}, 10^{5} \mathrm{CFU} / \mathrm{mL}$, and $10^{7} \mathrm{CFU} / \mathrm{mL}$ dilutions were prepared. Each $1200 \mathrm{~g}$ meat batch was then divided into four $300 \mathrm{~g}$ aliquots, three of which were contaminated with the different suspensions to obtain final contaminations of $10^{1} \mathrm{CFU} / \mathrm{g}, 10^{3} \mathrm{CFU} / \mathrm{g}$, and $10^{5} \mathrm{CFU} / \mathrm{g}$, as well as one with sterile saline solution as the negative control. From each aliquot, $25 \mathrm{~g}$ sampling units were prepared in triplicate and homogenized in a stomacher for $1 \mathrm{~min}$ with $225 \mathrm{~mL}$ of buffered peptone water (BPW) for Salmonella-contaminated samples or $225 \mathrm{~mL}$ of Preston broth for Campylobacter-contaminated samples. Bacterial suspensions cultured in the broth were used as positive controls and to evaluate the effect of matrix inhibition. All samples were then incubated as specified above. Ten $\mathrm{mL}$ of enrichment broth were collected in $15 \mathrm{~mL}$ tubes at time 0 and after 2,4 , and $6 \mathrm{~h}$, and stored at $-20^{\circ} \mathrm{C}$ until use.

Table 1. List of the ATCC/NCTC Salmonella and Campylobacter strains used to contaminate the minced chicken meat batches.

\begin{tabular}{ccc}
\hline & Salmonella spp. & Campylobacter spp. \\
\hline Strain 1 & S. Typhimurium (ATCC 6994) & C. jejuni (ATCC 33291) \\
\hline Strain 2 & S. Enteritidis (ATCC 13076) & C. jejuni (ATCC 49943) \\
\hline Strain 3 & S. Infantis (NCTC 6703) & C. coli (ATCC 43478) \\
\hline
\end{tabular}

\subsection{Pathogen Plate Count}

One $\mathrm{mL}$ from each contaminated sample, both the positive control (bacterial suspension) and negative control, was diluted in $9 \mathrm{~mL}$ of BPW, and 1:10 serial dilutions were prepared. For Salmonella spp. plate count, $0.1 \mathrm{~mL}$ of each dilution was plated on a Hektoen agar solid medium and incubated at $37^{\circ} \mathrm{C} \pm 1{ }^{\circ} \mathrm{C}$ for $21 \pm 3 \mathrm{~h}$. For Campylobacter spp. plate count, $0.1 \mathrm{~mL}$ of each dilution was plated on a modified charcoal cefaprazone deoxychocolate (MCDD) solid medium and incubated at $41.5^{\circ} \mathrm{C} \pm 0.5^{\circ} \mathrm{C}$ for $44 \pm 3 \mathrm{~h}$ under microaerophilia conditions. The bacterial concentration of each sample was estimated by counting colonies grown in plates in which a countable number of colonies (10 to 150) was observed. Each sample was measured in triplicate.

\subsection{DNA Extraction}

The $10 \mathrm{~mL}$ of enrichment broth previously collected were thawed at room temperature and centrifuged at $2000 \times g$ for 15 min to separate residual matrices. The supernatant was collected and centrifuged at $10,000 \times g 10 \mathrm{~min}$. The resulting pellet was then resuspended in $100 \mu \mathrm{L}$ of Chelex 100 (Biorad, Hercules, CA, USA) and transferred to a $1.5 \mathrm{~mL}$ tube. The 
suspension was incubated at $56{ }^{\circ} \mathrm{C}$ for $20 \mathrm{~min}$ and then at $99{ }^{\circ} \mathrm{C}$ for $15 \mathrm{~min}$. The tubes were then centrifuged at $12,000 \times \mathrm{g} 5 \mathrm{~min}$, and the supernatant was collected and stored at $-20^{\circ} \mathrm{C}$ until use.

\subsection{Real-Time PCR}

To evaluate LAMP performance, Salmonella and Campylobacter were also assayed by RT-PCR using commercial kits. Briefly, $5 \mu \mathrm{L}$ of probe and $5 \mu \mathrm{L}$ of extracted DNA were added to $40 \mu \mathrm{L}$ of a Mix IQ Check kit for Salmonella and an IQ Check kit for Campylobacter (Biorad, Hercules, CA, USA). The reaction was carried out in a CFX96 thermal cycler (Biorad, Hercules, CA, USA) with the following protocol: $95^{\circ} \mathrm{C}$ for $10 \mathrm{~min}$, followed by 50 cycles at $95^{\circ} \mathrm{C}$ for $15 \mathrm{~s}, 58^{\circ} \mathrm{C}$ for $20 \mathrm{~s}$, and $72{ }^{\circ} \mathrm{C}$ for $30 \mathrm{~s}$ (total amplification time: $90 \mathrm{~min}$ ).

\subsection{Colorimetric LAMP}

Colorimetric LAMP assays were carried out using primers previously described by Zhuang et al. [22] for Salmonella and by Romero et al. [23,24] for Campylobacter spp. (Table 2).

Table 2. List of LAMP primers used for the amplification of Salmonella enterica and Campylobacter spp., and the composition of the 10X primer mix used in the LAMP assays described.

\begin{tabular}{|c|c|c|}
\hline & 10X Mix Concentration & Primers for Salmonella spp. \\
\hline FIP & $16 \mu \mathrm{M}$ & 3'-TGCACTTTACCGGTACGCTGAATACAGCGGCAATTTCAACCA-5' \\
\hline BIP & $16 \mu \mathrm{M}$ & 3'-CGGTCTGGATTCGCAGGTCAAAGCGATAGCCTGGGGAAC-5' \\
\hline F3 & $2 \mu \mathrm{M}$ & $3^{\prime}$-CCGGACAAACGATTCTGGTA-5' \\
\hline B3 & $2 \mu \mathrm{M}$ & 3'-CCGACATCGGCATTATCCG-5' \\
\hline LF & $4 \mu \mathrm{M}$ & 3'-TACCCCCTCCGGCTTTTG-5' \\
\hline LB & $4 \mu \mathrm{M}$ & 3'-ACAATGCGTCTTATCGCTACG-5' \\
\hline & & Primers for Campylobacter spp. \\
\hline FIP & $16 \mu \mathrm{M}$ & 3'-GGACCGTGTCTCAGTTCCAGTGTGACGGATGAGACTATATAGTATCAGCTAG-5' \\
\hline BIP & $16 \mu \mathrm{M}$ & 3'-CGGGAGGCAGCAGTAGGGAATATTGCTAAGAAAAGGAGTTTACGCTCCG-5’ \\
\hline F3 & $2 \mu \mathrm{M}$ & 3'-CTGCTTAACACAAGTTGAGTAGG-5' \\
\hline B3 & $2 \mu \mathrm{M}$ & 3'-TTCCTTAGGTACCGTCAGAA-5' \\
\hline LF & $4 \mu \mathrm{M}$ & 3'-GTTAAGCGTCATAGCCTTGGTAA-5' \\
\hline $\mathrm{LB}$ & $4 \mu \mathrm{M}$ & 3'-GCGTGGAGGATGACACTT-5' \\
\hline
\end{tabular}

The reaction mixture was set up with $12.5 \mu \mathrm{L}$ of WarmStart Colorimetric LAMP 2X Master Mix (New England Biolabs, Ipswich, MA, USA), $2.5 \mu \mathrm{L}$ of 10X Primer mix (Table 2), and $2 \mu \mathrm{L}$ of DNA (PCR-grade water for negative controls) from Salmonella or Campylobacter. PCR-grade water was added to reach a final volume of $25 \mu \mathrm{L}$.

Colorimetric LAMP results were visualized by the naked eye, as the color of the mix shifted from bright red to yellow in the case of positive amplification. LAMP reactions were carried out at $65^{\circ} \mathrm{C}$ for $30 \mathrm{~min}$ (hereafter referred as $30^{\prime} \mathrm{LAMP}$ ) and $45 \mathrm{~min}$ (hereafter referred as $45^{\prime}$ LAMP) on a heated plate equipped with $0.2 \mathrm{~mL}$ tube adaptors. LAMP assay specificity was also tested against some of the most common foodborne pathogens, namely Yersinia enterocolitica, Listeria monocytogenes, and verocytotoxin-producing E. coli.

\subsection{Statistical Analysis}

The concordance of LAMP and RT-PCR results was assessed by McNemar's and binomial tests. Linear regression was used to evaluate the linearity of RT-PCR results in relation to the different enrichment times and contamination levels. Data analysis was conducted by open-source software $\mathrm{R}$ (3.4.3 version).

\section{Results}

\subsection{Pathogen Plate Count}

According to pathogen plate count, both Salmonella and Campylobacter grew as expected. In Salmonella-contaminated samples, the pathogen showed exponential growth 
beginning after $2 \mathrm{~h}$ of enrichment (Figure 1a,b). Indeed, Salmonella is characterized by rapid growth if cultured under ideal conditions. On the other hand, Campylobacter-contaminated samples showed a slower growth rate, with no exponential growth observed in the considered enrichment time (Figure 1c,d); this is explained by the longer time normally required for this pathogen's growth.

(a)

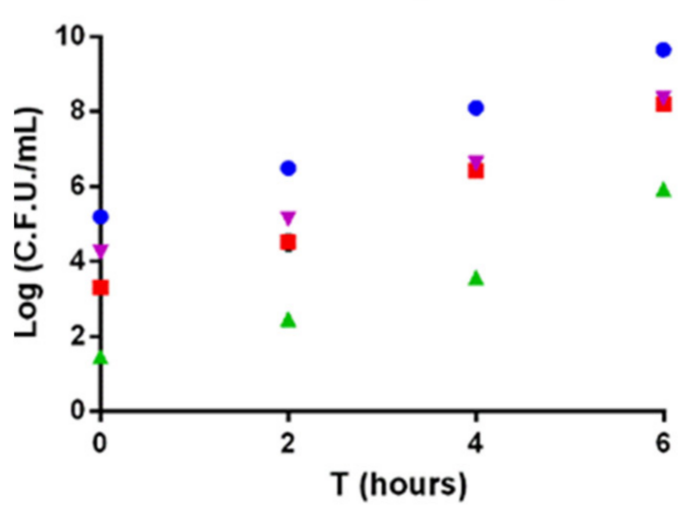

(c)

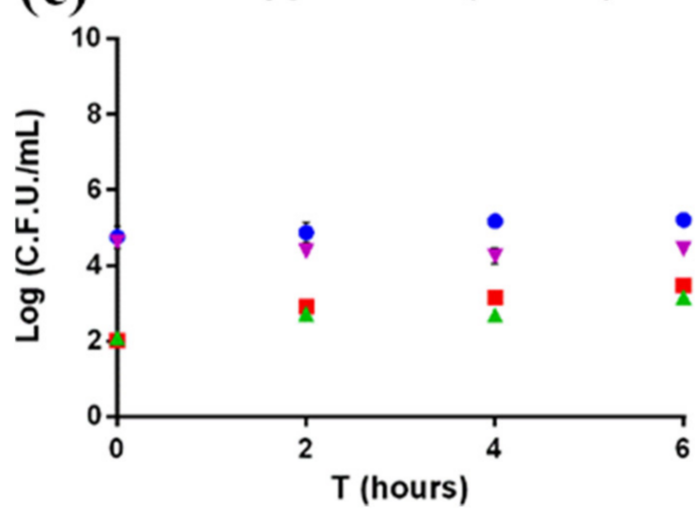

(b)

Salmonella (batch 2)

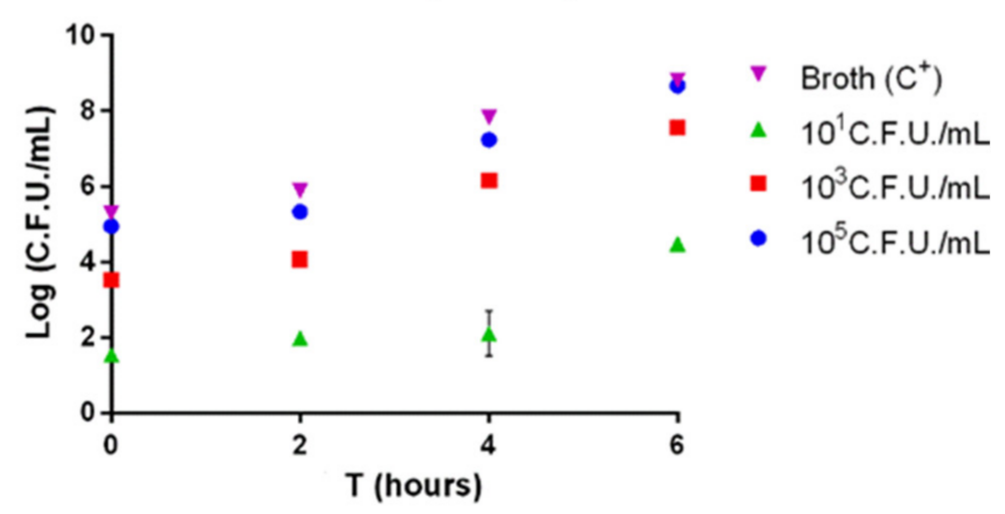

(d) Campylobacter (batch 2)

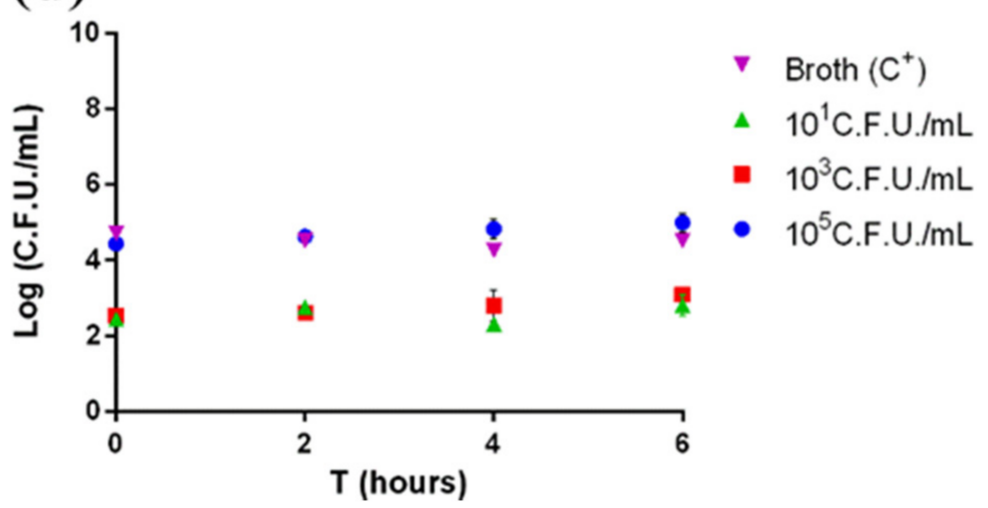

Figure 1. (a,b) Salmonella and (c,d) Campylobacter plate count. Each sample was measured in triplicate. Mean $\pm \mathrm{SD}$ is shown. The full dataset can be found in Table S1.

\subsection{Colorimetric LAMP Specificity and Inclusivity Tests}

The most common hurdle in LAMP assays is unspecific amplification. To verify primer specificity, the colorimetric LAMP for Salmonella and Campylobacter was tested against other common foodborne pathogens, such as Y. enterocolitica, L. monocytogenes, and verocytotoxin-producing E. coli. As shown in (Figure 2), primers appeared to be specific for the two target pathogens, as DNA amplification (with a subsequent color shift from red to yellow) occurred only in the tubes containing Salmonella and Campylobacter DNA.

Morover, to verify inclusivity, the primers were tested separately on all strains used for the contamination and on a number of field strains isolated from poultry meat (Figure S1). 
(a)

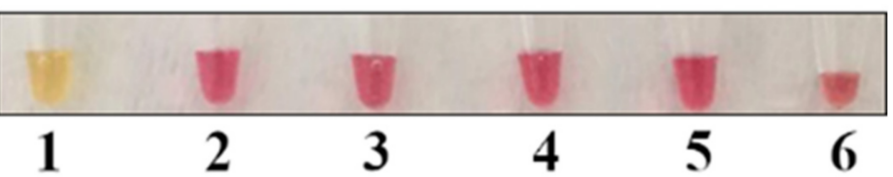

(b)

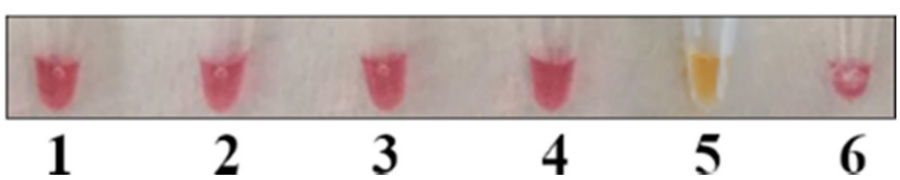

Figure 2. LAMP specificity test. The sample positivity was verified by observing the change in the color of the mix (from red to yellow). (a) LAMP for Salmonella spp. detection; (b) LAMP for Campylobacter spp. detection. Legend: $1=$ S. enterica; $2=$ L. monocytogenes; $3=$ Y. enterocolitica; 4 = verocytotoxin-producing E. coli; 5 = C. jejuni; and $6=$ negative control.

\subsection{Real-Time PCR and LAMP for Salmonella}

Our data (Figure 3) highlighted that the real-time PCR could detect Salmonella at the lowest concentration tested $\left(10^{1} \mathrm{CFU} / \mathrm{g}\right)$ after shorter enrichment times than those described in the ISO 6579-2:2017 procedure $(18 \mathrm{~h})$. Even at the lowest concentrations $\left(10^{1} \mathrm{CFU} / \mathrm{g}\right)$ and at amplification times as short as $45^{\prime}, 89$ out of the 96 positive samples were correctly detected $(92.7 \%$, results shown in Table S2). All amplified samples showed a Ct between 39 and 22 and were therefore considered positive according to AFNOR BRD 07/06-07/04 (Ct $\geq 10)$. Enrichment incubation times against $\mathrm{Ct}$ values were fitted by linear regression for $10^{3} \mathrm{CFU} / \mathrm{g}$ and $10^{5} \mathrm{CFU} / \mathrm{g}$ concentrations. The $\mathrm{Ct}$ values for both concentrations tested were characterized by a significant linear trend $(p<0.05)$, suggesting that replication of the bacteria already takes place in the first hours of enrichment.
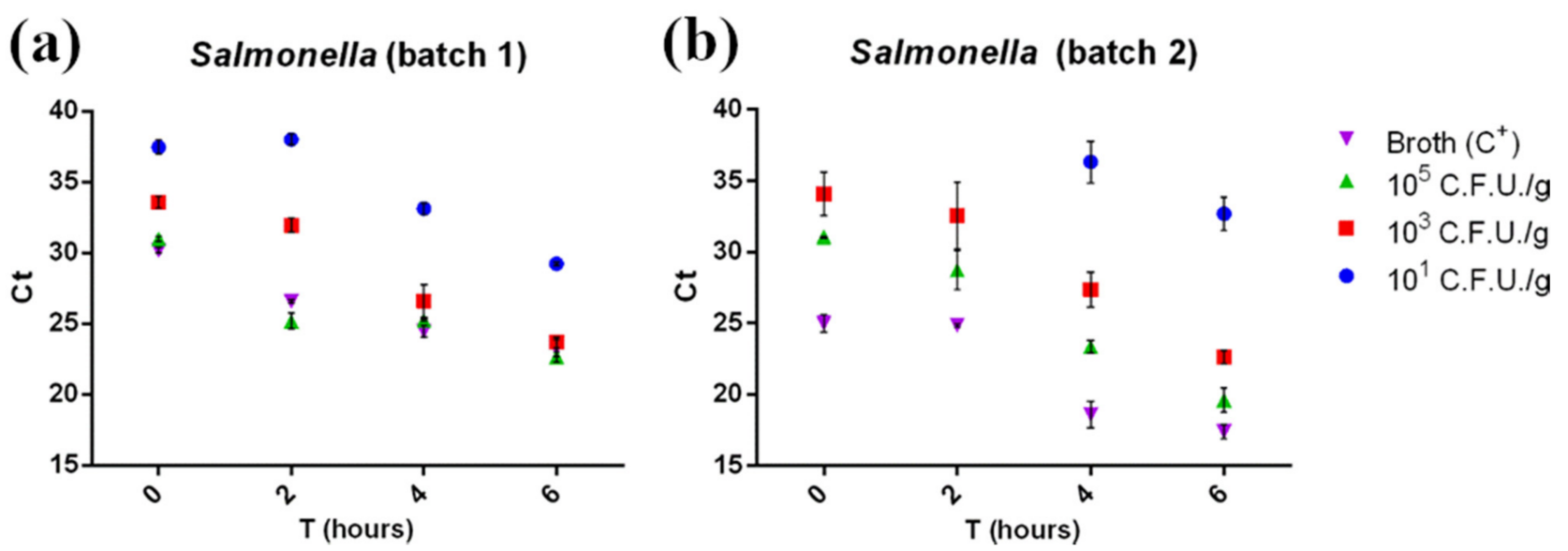

Figure 3. Ct of the first batch (a) and the second batch (b) of minced chicken meat samples contaminated with Salmonella plotted against related enrichment times $(0,2,4$, and $6 \mathrm{~h})$. Ct was inversely correlated with enrichment time and bacterial concentration. No amplification was detected at the $10^{1} \mathrm{CFU} / \mathrm{g}$ contamination level T0 and T2 samples in batch 2 . Measurements were performed on two separate batches of minced chicken meat in triplicate. The mean $\pm \mathrm{SD}$ of each measurement is shown. The full dataset can be found in Table S3a.

Moreover, Ct comparison between the samples and positive control (broth + Salmonella $105 \mathrm{CFU} / \mathrm{g}$ ) suggested a low matrix inhibition effect on RT-PCR, since the Ct values for the positive control (105 CFU/g in broth) and for $105 \mathrm{CFU} / \mathrm{g}$ contaminated samples were comparable. Regarding the colorimetric LAMP assay, after a $30^{\prime}$ reac-tion, a total of 78 out of 96 samples were found positive ( $81.3 \%$, see Table S2). Con-cerning $30^{\prime}$ LAMP, $101 \mathrm{CFU} / \mathrm{g}$ contaminated samples were detected at T6 in batch 1 and at T4 in batch 2 
(Figures S2 and S4), while the $45^{\prime}$ LAMP assay detected in 93 out of 96 samples (96.6\%), and the reaction was positive even for the $101 \mathrm{CFU} / \mathrm{g}$ T0 samples in batch 1 (Figure 4a) and $101 \mathrm{CFU} / \mathrm{g}$ T2 samples for batch 2 (Figure 4b). The real-time PCR was able to detect the same samples, even without any enrichment phase (101 CFU/g T0 (Figure 3a), blue dots). Real-time PCR and colorimetric LAMP results were then compared using McNemar's and binomial tests. A significant difference $(p<0.05)$ was observed between real-time PCR and $30^{\prime}$ LAMP and between $45^{\prime}$ LAMP and $30^{\prime}$ LAMP in favor of real-time PCR and $45^{\prime}$ LAMP, respectively, while no significant dif-ference was observed between real-time PCR and $45^{\prime}$ LAMP results $(p>0.05)$.

(a)

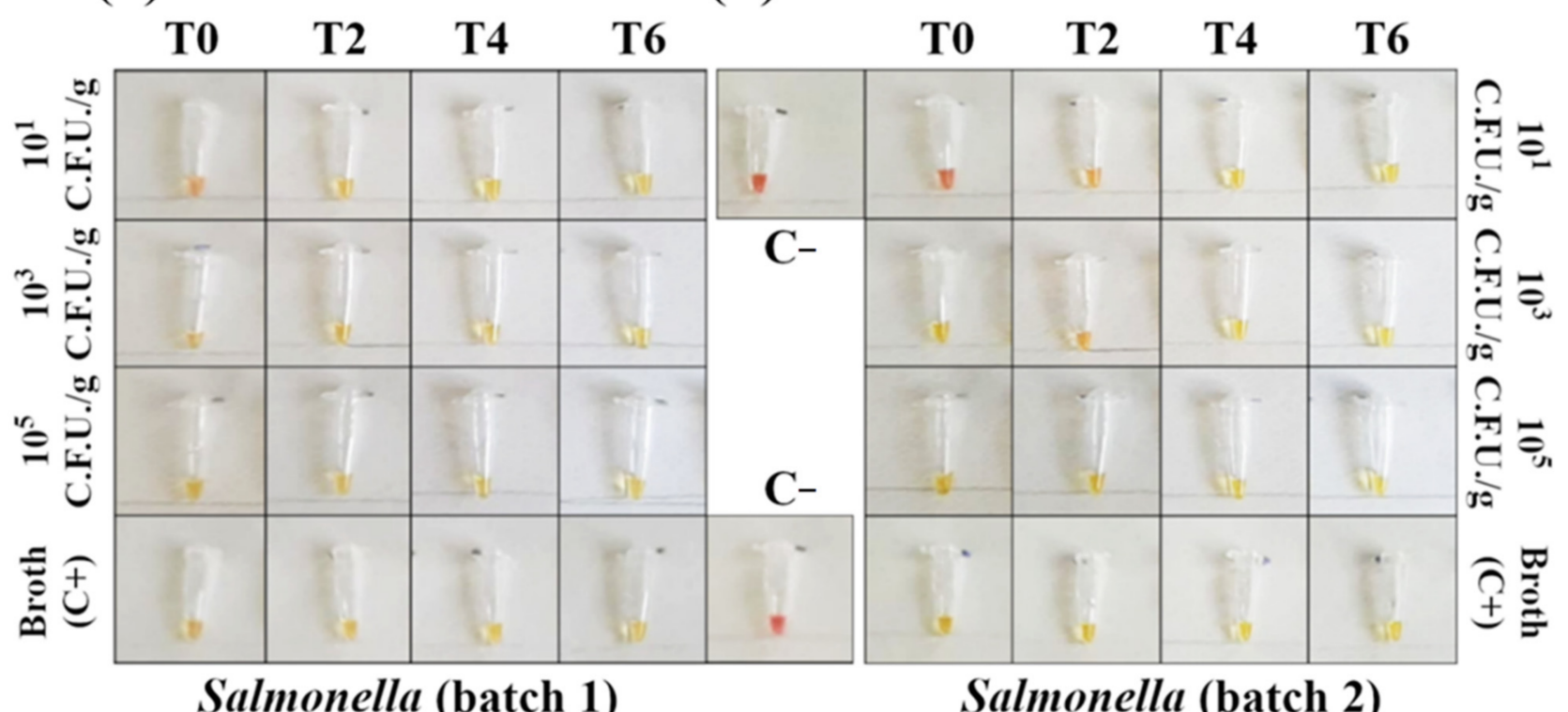

Figure 4. Detection of Salmonella DNA in contaminated minced chicken meat using colorimetric LAMP (amplification time $\left.45^{\prime}\right)$. Negative samples are red and positive samples are yellow. (a) In the first batch of minced meat, the reaction detected $10^{1} \mathrm{CFU} / \mathrm{g}$ with no need for an enrichment phase. (b) For the second batch, the reaction amplified $10^{1} \mathrm{CFU} / \mathrm{g}$ after $2 \mathrm{~h}$ of enrichment. Each sample was tested in triplicate (see Figures S3 and S5 for the complete panels).

\subsection{RT-PCR and LAMP for Campylobacter}

RT-PCR detected Campylobacter starting from a concentration of $10^{3} \mathrm{CFU} / \mathrm{g}$ in both minced chicken meat batches, with no need for an enrichment phase (Figure 5, red squares). However, it failed to detect $10^{1} \mathrm{CFU} / \mathrm{g}$ contaminated samples at all enrichment times tested (Figure 5, blue dots). Campylobacter's Ct values were barely influenced by the enrichment time (Figure 5) and mirrored the results from pathogen plate count (Figure 1b) according to the pathogen slow growth rate. This was confirmed by the statistical analysis, where no linear trend was observed $(p>0.05)$. 
(a)

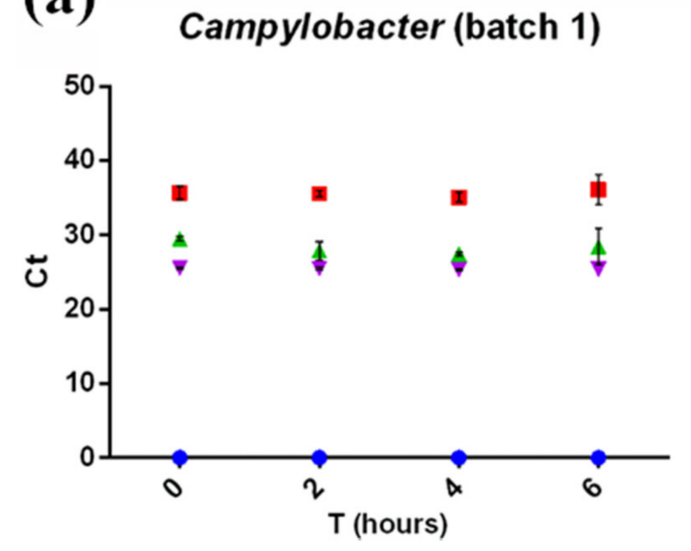

(b)

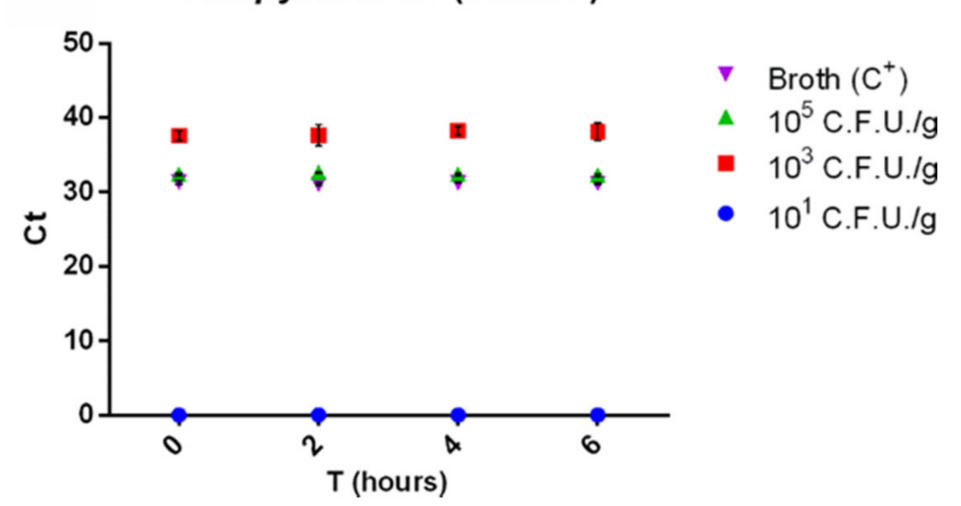

Figure 5. Ct of the first batch (a) and the second batch (b) of minced chicken meat contaminated with Campylobacter spp. plotted against enrichment times $(0,2,4$, and $6 \mathrm{~h})$. Ct was inversely correlated with the starting contamination level, but not with enrichment time, highlighting the slow-growing rate of the pathogen. No amplification was detected in $10^{1} \mathrm{CFU} / \mathrm{g}$ contaminated samples. Measurements were performed on two separate batches of minced chicken meat in triplicate. The mean \pm SD of each measurement is shown. The full dataset can be found in Table S3b.

Overall, a total of 71 out of 96 positive samples were correctly detected ( $74 \%$ of the total samples, see Table S2 for summarized results).

As for Salmonella, Ct comparison between the samples and positive control (broth + Campylobacter $10^{5} \mathrm{CFU} / \mathrm{g}$ ) suggested a minimal matrix inhibition effect. The $30^{\prime}$ LAMP reaction for Campylobacter spp. detection provided results identical to the RT-PCR, with positive outcomes starting from $10^{3} \mathrm{CFU} / \mathrm{g}$ at $\mathrm{T} 0$ (Figures S6 and S8). Negative results were obtained for all $10^{1} \mathrm{CFU} / \mathrm{g}$ contaminations (Figures S6 and S8). By extending the LAMP reaction for 15 additional minutes, the number of samples detected positive increased (82 out of 96 samples, $82.5 \%$ positivity, Table S2), with $10^{1} \mathrm{CFU} / \mathrm{g}$ samples being detected at T4 in batch 1 (Figure 6a). Again, $45^{\prime}$ LAMP and RT-PCR results were compared using McNemar's and binomial tests, and, in this case, they were significantly different $(p<0.05)$ in favor of the LAMP assay.

(a)

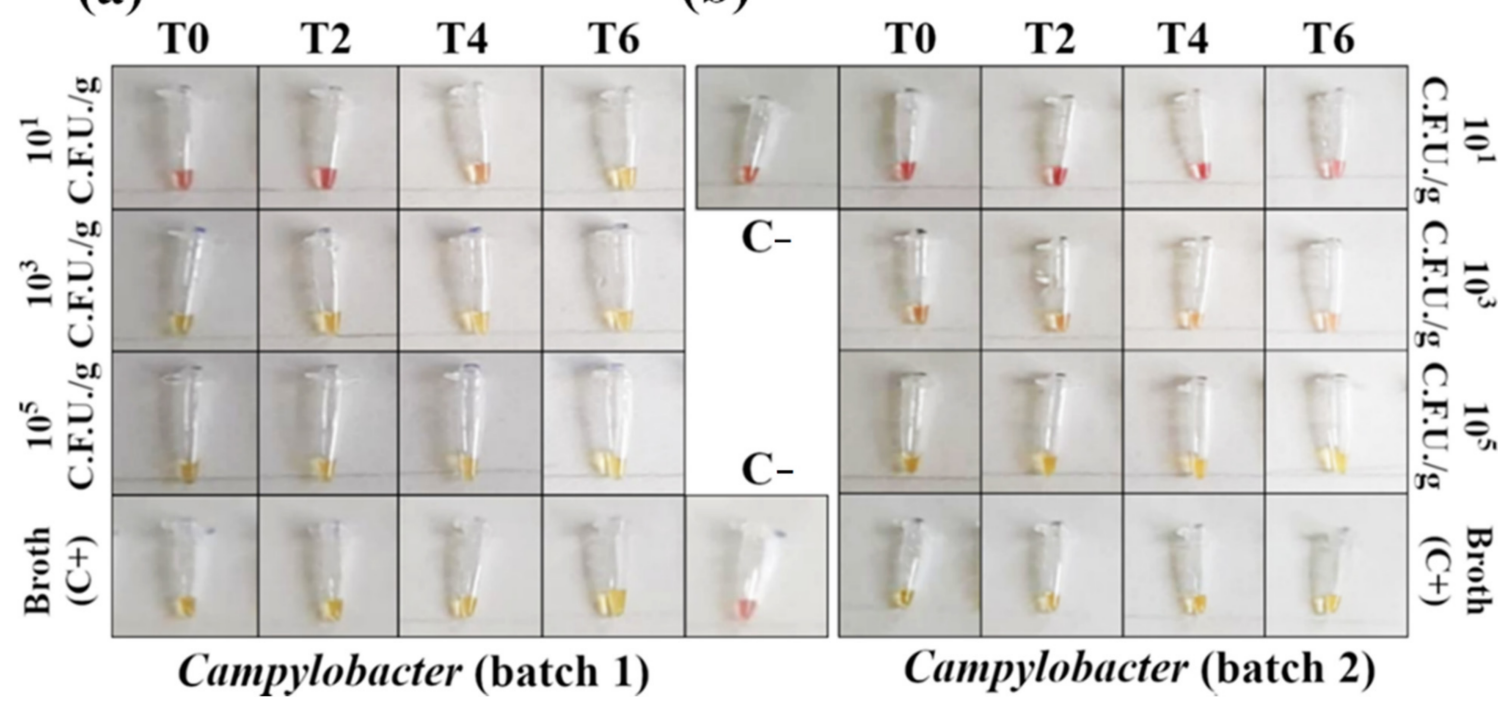

Figure 6. Detection of Campylobacter spp. DNA in contaminated minced chicken meat using colorimetric LAMP (amplification time $45^{\prime}$ ). Negative samples are red and positive samples are yellow. (a) In the first batch of minced meat, the reaction detected $10^{1} \mathrm{CFU} / \mathrm{g}$ after $4 \mathrm{~h}$ of enrichment. (b) For the second batch, $10^{3} \mathrm{CFU} / \mathrm{g}$ were detected with no need for enrichment. Only one out of three replicates is shown here for each sample (see Figures S7 and S9 for the complete panels). 


\section{Discussion}

To date, most of the time required to detect food pathogens is spent in the enrichment of the microorganism of interest (Salmonella enterica and Campylobacter spp. in this specific case). Therefore, in our study, we evaluated the reduction of the enrichment phase to shorten the total analysis time without affecting pathogen detection. In particular, the detection of Salmonella spp. and Campylobacter spp. was assessed after 0, 2, 4, or $6 \mathrm{~h}$, instead of $18 \mathrm{~h}$ and $24 \mathrm{~h}$, respectively. A second time-saving step is represented by the implementation of a DNA amplification method that can give results at a glance, without the need for further sample processing (i.e., agarose gel electrophoresis). Contaminated samples were thus analyzed with a routinely used RT-PCR commercial kit and with a colorimetric LAMP. Concerning Salmonella detection, both methods proved feasible and had comparable performances, despite $30^{\prime}$ LAMP proving to be slightly lower performing than RT-PCR $(p<0.05)$, since $10^{1} \mathrm{CFU} / \mathrm{g}$ of Salmonella were detected after $6 \mathrm{~h}$ and $4 \mathrm{~h}$ of enrichment in batch 1 and 2, respectively (Figures S2 and S4) in accordance with plate count results, showing an exponential growth already beginning after $2 \mathrm{~h}$ of enrichment (Figure 1a,b). However, $45^{\prime}$ LAMP detected $96.6 \%$ positive samples, showing performances comparable to RT-PCR $(p<0.05)$, according to most studies presenting RT-PCR with limits of detection rather similar to LAMP [8]. Moreover, the $45^{\prime}$ assay was positive for the $10^{1} \mathrm{CFU} / \mathrm{g} \mathrm{sam}$ ples after a $2 \mathrm{~h}$ enrichment, and even without enrichment in batch 1 (Figure $4 \mathrm{a}, \mathrm{b}$ ). These results were consistent with a recent study, which detected after $2 \mathrm{~h}$ of enrichment all of the spiked samples as $100 \%$ positive by conventional $45^{\prime}$ LAMP [25], while, without the enrichment step, the reported sensitivity varied from $2.2 \mathrm{CFU} / \mathrm{g}$ to $10^{8} \mathrm{CFU} / \mathrm{mL}$ [8]. However, compared to conventional LAMP, the colorimetric assay enables an easy detection of positive samples without any additional processing or specialist interposition, allowing field-based diagnostics.

Regarding Campylobacter, RT-PCR and 30' LAMP detected Campylobacter spp. starting from a concentration of $10^{3} \mathrm{CFU} / \mathrm{g}$ without enrichment (Figures 5 and 6). Performing $45^{\prime}$ LAMP significantly increased the number of detected positive samples (from $74 \%$ to $82.5 \%$, Table S2), with $10^{1} \mathrm{CFU} / \mathrm{g}$ samples being detected after $4 \mathrm{~h}$ of enrichment (Figure 6a). In a study on artificially contaminated swabs, the limit of detection of $60^{\prime}$ LAMP was reported between $10^{3}$ and $10^{4} \mathrm{CFU} /$ swab [24]. In fact, with our protocol, the increase to $60^{\prime}$ of the colorimetric LAMP resulted in the production of false positives, with a decrease in specificity (data not shown); however, the $30^{\prime}$ or $45^{\prime}$ protocol detected down to $10^{3} \mathrm{CFU} / \mathrm{g}$ without enrichment. The results of Campylobacter detection with our protocol is consistent with the slow growth rate featured by Campylobacter spp., as also demonstrated by plate count results (Figure 1c,d). Indeed, the enrichment phase for Campylobacter spp. usually takes more than double the time compared to Salmonella $(24 \mathrm{~h}$ vs. $18 \mathrm{~h}$ ). Our results suggest that LAMP can outperform real-time PCR in detecting Campylobacter, giving a better outcome in half of the time $\left(45^{\prime}\right.$ vs. $\left.90^{\prime}, p<0.05\right)$, and stressing the impact of fast results for the poultry industry, where timely detection is often crucial [20].

With LAMP, the amplification of $10^{1} \mathrm{CFU} / \mathrm{g}$ contaminated samples was not always successful, suggesting that this bacterial concentration may be below the limit of detection of this protocol. Overall, our results show that colorimetric LAMP might be suitable for Salmonella and Campylobacter spp. detection, since, for Salmonella, even the lowest concentration is successfully detected after $6 \mathrm{~h}$ of enrichment, and, for Campylobacter, it is possible to detect $10^{3} \mathrm{CFU} / \mathrm{g}$, meeting the limits set by the EC Regulation No. 2073/2005 regarding Campylobacter detection in broiler carcasses [26], potentially providing food business operators a tool for the rapid screening of these pathogens. The present study highlights the possibility to perform a Salmonella and Campylobacter screening in less than $8 \mathrm{~h}$ from specimen receipt, using either RT-PCR or colorimetric LAMP and with minimal differences in terms of sensitivity. Indeed, LAMP is highly specific due to six primers that efficiently amplify the target DNA, resulting in $10^{9}$ copies in less than $1 \mathrm{~h}$, while RT-PCR produces a DNA amount almost 20 times lesser in about $1-2 \mathrm{~h}[8,27,28]$. However, even if both techniques proved equally good for one-day detection of the foodborne pathogens 
analyzed, the colorimetric LAMP has the additional advantages of speed, simplicity, and portability. Indeed, four aspects tip the scale in favor of the LAMP technique: (i) the time needed for colorimetric LAMP to obtain a result is half the time needed for RT-PCR ( $45^{\prime}$ vs. $90^{\prime}$ ); (ii) the reaction does not require complex instrumentation, since a common heated plate is sufficient (no thermal cycler); (iii) the colorimetric LAMP outcome can be instantly determined by observing the color of the amplification mix (red if negative, yellow if positive, and no fluorescence detectors are needed); and (iv) the risk of environmental contamination by amplified DNA is greatly reduced (the reaction tube does not need to be opened during the detection phase). The second and third points, in particular, give colorimetric LAMP a remarkable edge over RT-PCR, especially if pathogen screening is conducted in environments lacking the proper specialized instrumentation (e.g., for supply chain tests or on-field analyses). Moreover, the naked eye visualization of LAMP products is a promising system already used as a fast and direct diagnostic assay [20,29]. Nevertheless, colorimetric LAMP is not free from uncertainty, as its colorimetric nature under particular conditions (e.g., a very low starting amount of target DNA) leaves space for subjective interpretation when the color shift occurs only partially, featuring orange nuances (see Figures S6-S9). To mitigate this limit, three precautions could be applied: (i) analyze replicates of the same sample and consider it as positive when at least one of them is unquestionably yellow; (ii) increase the starting amount of DNA in the mix; and (iii) further extend the amplification phase by 5 or $10 \mathrm{~min}$.

Regardless of the DNA amplification technique used, the use of a shortened enrichment phase or direct amplification could prove useful in specific situations, such as for self-monitoring purposes or for goods being held for import inspection purposes. Finally, it is worth specifying that this study is a proof of concept, since it was conducted under ideal conditions using experimentally contaminated specimens, but, due to LAMP's high tolerance to potential assay inhibitors, it is a suitable and robust method to detect pathogens in food matrices at the POC [8]. Further analyses are required to ensure that the methodologies tested here are also fully applicable to matrices other than minced chicken meat and to naturally contaminated samples.

Supplementary Materials: The following are available online at https:/ /www.mdpi.com/article/10 .3390/foods10051132/s1, Supplementary Materials 1, containing: Tables S1-S3, and Figures S1-S9.

Author Contributions: Conceptualization: D.D.M., A.Z., and V.F.; Methodology: A.Z., E.C.-C., B.B., and V.F.; Formal analysis: A.Z., N.F., V.C., and L.R.; Data curation: E.C.-C., A.Z., L.R., and B.B.; Writing—original draft preparation: A.Z., V.C., and L.R.; Writing—review and editing: A.Z., L.R., V.F., and S.A.; Visualization: A.Z.; Supervision: P.A.-M. and M.N.L.; Project administration: D.D.M.; Funding acquisition: D.D.M. All authors have read and agreed to the published version of the manuscript.

Funding: This research and APC were supported through the REFIN project "Innovative one-day molecular methods to evaluate the compliance of European Regulation microbiological criteria in Food" (project ID: RF-2016-02364002) funded by Ministero della Salute.

Institutional Review Board Statement: Not applicable.

Informed Consent Statement: Not applicable.

Data Availability Statement: The data in the presented study are available within the article and in the Supplementary Materials (file name: LAMP_supp_mat).

Conflicts of Interest: The authors declare no conflict of interest.

\section{References}

1. EFSA; ECDC. The European Union One Health 2019 Zoonoses Report. EFSA J. 2021, 19, e06406. Available online: https: / / efsa.onlinelibrary.wiley.com/doi/abs/10.2903/j.efsa.2021.6406 (accessed on 20 April 2021). [CrossRef]

2. Antunes, P.; Mourão, J.; Campos, J.; Peixe, L. Salmonellosis: The role of poultry meat. Clin. Microbiol. Infect. 2016, 22, 110-121. Available online: https:/ / pubmed.ncbi.nlm.nih.gov/?term=antunes+2016+salmonellosis (accessed on 20 April 2021). [CrossRef] 
3. Jajere, S.M. A review of Salmonella enterica with particular focus on the pathogenicity and virulence factors, host specificity and antimicrobial resistance including multidrug resistance. Vet. World 2019, 12, 504-521. Available online: https://pubmed.ncbi.nlm. nih.gov / ?term=jajere+2019 (accessed on 20 April 2021). [CrossRef] [PubMed]

4. Bryan, F.L.; Doyle, M.P. Health Risks and Consequences of Salmonella and Campylobacter jejuni in Raw Poultry. J. Food Prot. 1995, 58, 326-344. Available online: https://pubmed.ncbi.nlm.nih.gov/?term=bryan+1995+salmonella (accessed on 20 April 2021). [CrossRef] [PubMed]

5. Facciolà, A.; Riso, R.; Avventuroso, E.; Visalli, G.; Delia, S.A.; Laganà, P. Campylobacter: From microbiology to prevention. J. Prev. Med. Hyg. 2017, 58, E79-E92. Available online: https://pubmed.ncbi.nlm.nih.gov/?term=facciola+2017 (accessed on 20 April 2021).

6. Mughini-Gras, L.; Enserink, R.; Friesema, I.; Heck, M.; van Duynhoven, Y.; van Pelt, W. Risk factors for human salmonellosis originating from pigs, cattle, broiler chickens and egg laying hens: A combined case-control and source attribution analysis. PLoS ONE 2014, 9, e87933. Available online: https:/ / pubmed.ncbi.nlm.nih.gov/?term=mughini-gras+2014+risk+factors (accessed on 20 April 2021). [CrossRef]

7. Bodulev, O.L.; Sakharov, I.Y. Isothermal Nucleic Acid Amplification Techniques and Their Use in Bioanalysis. Biochemistry (Mosc) 2020, 85, 147-166. Available online: https:/ / pubmed.ncbi.nlm.nih.gov/?term=bodulev+2020 (accessed on 20 April 2021). [CrossRef]

8. Yang, Q.; Domesle, K.J.; Ge, B. Loop-Mediated Isothermal Amplification for Salmonella Detection in Food and Feed: Current Applications and Future Directions. Foodborne Pathog. Dis. 2018, 15, 309-331. Available online: https://pubmed.ncbi.nlm.nih. gov/?term=yang+2018+loop-mediated+salmonella+ (accessed on 20 April 2021). [CrossRef]

9. Maruyama, F.; Kenzaka, T.; Yamaguchi, N.; Tani, K.; Nasu, M. Detection of bacteria carrying the stx2 gene by in situ loop-mediated isothermal amplification. Appl. Environ. Microbiol. 2003, 69, 5023-5028. [CrossRef]

10. Kaneko, H.; Iida, T.; Aoki, K.; Ohno, S.; Suzutani, T. Sensitive and rapid detection of herpes simplex virus and varicellazoster virus DNA by loop-mediated isothermal amplification. J. Clin. Microbiol. 2005, 43, 3290-3296. Available online: https: //pubmed.ncbi.nlm.nih.gov/?term=kaneko+2005+herpes (accessed on 20 April 2021). [CrossRef]

11. Enomoto, Y.; Yoshikawa, T.; Ihira, M.; Akimoto, S.; Miyake, F.; Usui, C.; Suga, S.; Suzuki, K.; Kawana, T.; Nishiyama, Y.; et al. Rapid diagnosis of herpes simplex virus infection by a loop-mediated isothermal amplification method. J. Clin. Microbiol. 2005, 43, 951-955. Available online: https:/ / pubmed.ncbi.nlm.nih.gov/?term=enomoto+2005+herpes (accessed on 20 April 2021). [CrossRef]

12. Lau, Y.L.; Meganathan, P.; Sonaimuthu, P.; Thiruvengadam, G.; Nissapatorn, V.; Chen, Y. Specific, sensitive, and rapid diagnosis of active toxoplasmosis by a loop-mediated isothermal amplification method using blood samples from patients. J. Clin. Microbiol. 2010, 48, 3698-3702. Available online: https:/ / pubmed.ncbi.nlm.nih.gov/?term=lau+2010+toxoplasmosis (accessed on 20 April 2021). [CrossRef]

13. Li, Y.; Fan, P.; Zhou, S.; Zhang, L. Loop-mediated isothermal amplification (LAMP): A novel rapid detection platform for pathogens. Microb. Pathog. 2017, 107, 54-61. Available online: https://pubmed.ncbi.nlm.nih.gov/?term=li+2017+LAMP (accessed on 20 April 2021). [CrossRef]

14. Zhao, X.; Li, Y.; Wang, L.; You, L.; Xu, Z.; Li, L.; He, X.; Liu, Y.; Wang, J.; Yang, L. Development and application of a loop-mediated isothermal amplification method on rapid detection Escherichia coli O157 strains from food samples. Mol. Biol. Rep. 2010, 37, 2183-2188. Available online: https://pubmed.ncbi.nlm.nih.gov/?term=zhao+2010+O157 (accessed on 20 April 2021). [CrossRef] [PubMed]

15. Wang, L.; Li, Y.; Chu, J.; Xu, Z.; Zhong, Q. Development and application of a simple loop-mediated isothermal amplification method on rapid detection of Listeria monocytogenes strains. Mol. Biol. Rep. 2012, 39, 445-449. Available online: https: / / pubmed.ncbi.nlm.nih.gov / ?term=wang+2012+development+listeria (accessed on 20 April 2021). [CrossRef] [PubMed]

16. Misawa, Y.; Yoshida, A.; Saito, R.; Yoshida, H.; Okuzumi, K.; Ito, N.; Okada, M.; Moriya, K.; Koike, K. Application of loop-mediated isothermal amplification technique to rapid and direct detection of methicillin-resistant Staphylococcus aureus (MRSA) in blood cultures. J. Infect. Chemother. 2007, 13, 134-140. Available online: https://pubmed.ncbi.nlm.nih.gov/?term=misawa+2007+MRSA (accessed on 20 April 2021). [CrossRef] [PubMed]

17. Xu, Z.; Li, L.; Chu, J.; Peters, B.M.; Harris, M.L.; Li, B.; Shi, L.; Shirtliff, M.E. Development and application of loop-mediated isothermal amplification assays on rapid detection of various types of staphylococci strains. Food Res. Int. 2012, 47, 166-173. Available online: https:/ / pubmed.ncbi.nlm.nih.gov/?term=xu+2012+staphylococci (accessed on 20 April 2021). [CrossRef]

18. Notomi, T.; Okayama, H.; Masubuchi, H.; Yonekawa, T.; Watanabe, K.; Amino, N.; Hase, T. Loop-mediated isothermal amplification of DNA. Nucleic Acids Res. 2000, 28, E63. Available online: https://pubmed.ncbi.nlm.nih.gov/?term=notomi+2000 (accessed on 20 April 2021). [CrossRef] [PubMed]

19. Domesle, K.J.; Young, S.R.; Yang, Q.; Ge, B. Loop-Mediated Isothermal Amplification for Screening Salmonella in Animal Food and Confirming Salmonella from Culture Isolation. J. Vis. Exp. 2020. Available online: https: / pubmed.ncbi.nlm.nih.gov $/$ ?term= domesle+2020 (accessed on 20 April 2021). [CrossRef]

20. Quyen, T.L.; Nordentoft, S.; Vinayaka, A.C.; Ngo, T.A.; Engelsmenn, P.; Sun, Y.; Madsen, M.; Bang, D.D.; Wolff, A. A Sensitive, Specific and Simple Loop Mediated Isothermal Amplification Method for Rapid Detection of Campylobacter spp. in Broiler Production. Front. Microbiol. 2019, 10, 2443. [CrossRef] [PubMed] 
21. Dalzini, E.; Cosciani-Cunico, E.; Bernini, V.; Bertasi, B.; Losio, M.; Daminelli, P.; Varisco, G. Food control. Food Control 2015, 47, 306-311. Available online: https:/ /www.sciencedirect.com/science/article/pii/S0956713514003776 (accessed on 20 April 2021). [CrossRef]

22. Zhuang, L.; Gong, J.; Li, Q.; Zhu, C.; Yu, Y.; Dou, X.; Liu, X.; Xu, B.; Wang, C. Detection of Salmonella spp. by a loop-mediated isothermal amplification (LAMP) method targeting bcfD gene. Lett. Appl. Microbiol. 2014, 59, 658-664. [CrossRef] [PubMed]

23. Romero, M.R.; D'Agostino, M.; Arias, A.P.; Robles, S.; Casado, C.F.; Iturbe, L.O.; Lerma, O.G.; Andreou, M.; Cook, N. An immunomagnetic separation/loop-mediated isothermal amplification method for rapid direct detection of thermotolerant Campylobacter spp. during poultry production. J. Appl. Microbiol. 2016, 120, 469-477. [CrossRef] [PubMed]

24. Romero, M.R.; Cook, N. A Rapid LAMP-Based Method for Screening Poultry Samples for Campylobacter without Enrichment. Front. Microbiol. 2018, 9, 2401. [CrossRef]

25. Vichaibun, V.; Kanchanaphum, P. Quantitative LAMP and PCR Detection of Salmonella in Chicken Samples Collected from Local Markets around Pathum Thani Province, Thailand. Int. J. Food Sci. 2020, 2020, 8833173. [CrossRef] [PubMed]

26. EUR-Lex-32005R2073-EN-EUR-Lex. Available online: https://eur-lex.europa.eu/legal-content/IT/ALL/?uri=CELEX\% 3A32005R2073 (accessed on 21 April 2021).

27. Nagamine, K.; Hase, T.; Notomi, T. Accelerated reaction by loop-mediated isothermal amplification using loop primers. Mol. Cell Probes 2002, 16, 223-229. Available online: https:/ / pubmed.ncbi.nlm.nih.gov /?term=nagamine+2002 (accessed on 21 April 2021). [CrossRef] [PubMed]

28. Mashooq, M.; Kumar, D.; Niranjan, A.K.; Agarwal, R.K.; Rathore, R. Development and evaluation of probe based real time loop mediated isothermal amplification for Salmonella: A new tool for DNA quantification. J. Microbiol. Methods 2016, 126, 24-29. [CrossRef] [PubMed]

29. Xie, L.; Xie, Z.; Zhao, G.; Liu, J.; Pang, Y.; Deng, X.; Xie, Z.; Fan, Q.; Luo, S. A loop-mediated isothermal amplification assay for the visual detection of duck circovirus. Virol. J. 2014, 11, 76. Available online: https://pubmed.ncbi.nlm.nih.gov/?term=xie+2014 +circovirus (accessed on 21 April 2021). [CrossRef] 